\title{
Current Status and Trends in Inflammatory Bowel Disease Surgery in Korea: Analysis of Data in a Nationwide Registry
}

\author{
Se-Jin Baek ${ }^{1}$ Kil Yeon Lee ${ }^{2}$ Ki Hwan Song ${ }^{3}$, Chang Sik Yu ${ }^{4}$; for the Inflammatory Bowel Disease (IBD) \\ Study Group of the Korean Society of Coloproctology* \\ ${ }^{1}$ Department of Surgery, Korea University College of Medicine, Seoul; ${ }^{2}$ Department of Surgery, College of Medicine, Kyung Hee University, \\ Seoul; ${ }^{3}$ Goo Hospital, Daegu; ${ }^{4}$ Department of Surgery, Asan Medical Center, University of Ulsan College of Medicine, Seoul, Korea
}

Purpose: Inflammatory bowel disease (IBD) in Korea has been increasing in recent years, but accurate statistics about operations for IBD are lacking. The purpose of this study was to investigate the trends and current status of IBD surgeries in Korea.

Methods: Using a national database from the Korea Health Insurance Review and Assessment Service, we analyzed data from patients who underwent surgery for Crohn disease and ulcerative colitis from January 2009 to October 2016.

Results: The mean number of patients who underwent surgery for Crohn disease was 791.8 per year. Colorectal surgery, small bowel surgery, and anal surgery were performed fairly often $(31.2 \%, 29.4 \%, 39.4 \%$, respectively), and laparoscopic surgery continued to increase, recently exceeding $30 \%$. About $50 \%$ of Crohn patients used biologics before and after surgery, and those patients also underwent a relatively high rate of anal surgeries (44.2\%). The mean number of patients who underwent surgery for ulcerative colitis was 247.6 per year. Colorectal surgery accounted for more than half of all operations, and laparoscopic surgery has been increasing rapidly, having been performed in about $60 \%$ of patients in recent years. The incidence of colorectal cancer in patients with ulcerative colitis was very high and increased rapidly during the study period, reaching about $80 \%$.

Conclusion: The number of patients undergoing laparoscopic surgery for IBD in Korea has increased significantly. Biologics are actively used by patients with Crohn disease, with a high proportion of anal surgeries required. Many of the surgical indications for ulcerative colitis have shifted into colorectal cancer.

Keywords: Inflammatory bowel disease; Crohn disease; Ulcerative colitis; Laparoscopy; Colitis-associated cancer

\section{INTRODUCTION}

Inflammatory bowel diseases (IBDs), represented by Crohn disease (CD) and ulcerative colitis (UC), are chronic inflammatory diseases characterized by involvement of the gastrointestinal tract

Received: May 23, 2018 - Accepted: July 21, 2018

Correspondence to: Kil Yeon Lee, M.D.

Department of Surgery, College of Medicine, Kyung Hee University,

23 Kyungheedae-ro, Dongdaemun-gu, Seoul 02447, Korea

Tel: +82-2-958-8241, Fax: +82-2-966-9366

E-mail: kilyeonlee@khu.ac.kr

ORCID code: https://orcid.org/0000-0001-9424-9525

*Members are listed in the ACKNOWLEDGMENTS section.

(C) 2018 The Korean Society of Coloproctology

This is an open-access article distributed under the terms of the Creative Commons Attribution NonCommercial License (http://creativecommons.org/licenses/by-nc/4.0) which permits unrestricted noncommercial use, distribution, and reproduction in any medium, provided the original work is properly cited. and acute exacerbations. Patients with IBD are relatively rare in Korea, unlike in Western countries, but they are gradually increasing in Korea because of the recent westernization of lifestyles [13]. From 1986 to 2005, the mean annual incidence of CD was $0.53 / 10^{5}$ inhabitants, with an adjusted prevalence of $11.24 / 10^{5}$, and the incidence of UC was $1.51 / 10^{5}$, with an adjusted prevalence of $30.87 / 10^{5}$, representing increases of $0.05 / 10^{5}$ and $0.34 / 10^{5}$, respectively, at 5-year intervals [1, 2]. From 2006 to 2012, the mean annual incidence of $\mathrm{CD}$ increased significantly to $4.6 / 10^{5}$, and that of UC increased to $3.2 / 10^{5}$ [3]. Kim et al. [3] reported that the bowel resection rates at 1 and 5 years from 2006 to 2012 were 5.0\% and $9.1 \%$ for $\mathrm{CD}$ and $0.8 \%$ and $2.1 \%$ for $\mathrm{UC}$, respectively.

As the number of patients with IBD increases, the number of surgeries for IBD also increases. However, no accurate statistics for IBD surgeries in Korea have been reported. Our aim in this study was to confirm the current status and trends in IBD surgery in Korea. 


\section{METHODS}

We used data from the Korea Health Insurance Review and Assessment Service, enrolling patients with Crohn disease (K50) or ulcerative colitis (K51) as a main diagnosis that underwent surgery (Table 1) from January 2009 to October 2016. The collected variables included sex, age range, disease code, behavior code, year of surgery, number of surgeries, and cancer code if patients had colorectal cancer. The number of surgeries performed per year was analyzed overall and by sex and age. We also examined the use of laparoscopic surgery, the presence of colorectal cancer, and the use of biologics. We identified laparoscopic surgery by using behavior codes E7690 and E7691, supplemental codes $\mathrm{ADC03}, \mathrm{ADC04}, \mathrm{ADC05}$, and a request for treatment material N0031001 at the time of surgery. Colorectal cancer was identified by the use of codes C18, C19, or C20 in the year of the operation or before. We deemed biologics to have been used when the $\mathrm{L} 04 \mathrm{AB}$ code was used at any time during the study period, before or after surgery. As an Anatomical Therapeutic Chemical Classification System code 4, L04AB can identify only whether biologics were used; it cannot distinguish whether infliximab (L04AB02), adalimumab (L04AB04), or another biologic was used. This study was approved by the Institutional Review Board of Korea University Anam Hospital (approval number: 2018AN0219) and included a waiver of the requirement to obtain informed consent due to the secondary analysis of existing data.

Descriptive results are presented as the mean for continuous outcomes and as the frequency and percentage for categorical outcomes. To evaluate the annual change in variables, we used linear regression analyses. Statistical analyses were performed using IBM SPSS Statistics ver. 20.0 (IBM Co., Armonk, NY, USA).
P-values $<0.05$ were accepted as statistically significant. Because the data in 2016 were available until only October, we converted those data to $12 / 10$ values when calculating means or ratios.

\section{RESULTS}

\section{Crohn Disease}

In 2009, 597 operations for CD were performed; the number of surgeries then increased until 2013, and since then, it has decreased slightly (Fig. 1). The mean number of operations per year was 791.8 , of which $71.9 \%$ were performed in males and $28.1 \%$ in females. The sex ratio did not change significantly by year. More than half of the patients who underwent surgery for $\mathrm{CD}$ were in their 20's and 30's (20's, 35.9\%; 30's, 24.5\%). Patients in their teens accounted for $18.8 \%$ of the patients, their 40 's for $10.9 \%$, their 50 's for $5.2 \%$, their 60 's for $2.2 \%$, and their 70 's for $1.7 \%$; those older than 80 accounted for $0.4 \%$. Patients younger than 10 years of age accounted for only $0.3 \%$ of the surgeries. Three types of surgery for $\mathrm{CD}$ were performed comparatively evenly: colorectal surgery, 31.2\%; small bowel surgery, 29.4\%; and anal surgery, 39.4\% (Fig. 2A). Anal surgery for an anal abscess or fistula was the most common. Limited resections, such as hemicolectomies and segmental resections, dominated the colorectal surgeries.

The number of laparoscopic surgeries in CD patients has increased dramatically from $11.6 \%$ in 2009 to more than $30 \%$ in 2015 (Fig. 3A). This trend is more pronounced in women than men; $41.6 \%$ of women represented laparoscopic surgery cases in 2015. That marked increase in the use of laparoscopic surgery in women has led to a slight increase in the percentage of women who underwent laparoscopic surgery compared to the total number of patients (67.9\% for men and $32.1 \%$ for women). The age

Table 1. Operation code list

\begin{tabular}{lll}
\hline Surgery & \multicolumn{1}{c}{ Operative name } & \multicolumn{1}{c}{ Behavior code } \\
\hline Colorectal surgery & Hemicolectomy/lleocecectomy & QA671, Q2671 \\
& Segmental colectomy & QA673, Q2673 \\
& Subtotal/total colectomy & Q1261, Q1262, QA672, Q2672 \\
& Anterior resection & QA921, Q2921 \\
& Low anterior resection & QA922, Q2922, Q2927 \\
& Abdominoperineal resection & QA923, Q2923 \\
& Total proctocolectomy with ileostomy & QA925, Q2925 \\
& Total proctocolectomy with IPAA & QA926, Q2926 \\
Small bowel surgery & Hartmann's operation & QA679, Q2679 \\
& Resection of small intestine & Q2651, Q2650 \\
Anal surgery & Loop ileostomy & Q2792 \\
& Operation for intestinal obstruction & Q2691, Q2692 \\
\hline
\end{tabular}

IPAA, ileal-pouch anal anastomosis. 
distribution of patients who underwent laparoscopic surgery did not differ significantly from that for all operations $(15.1 \%$ for patients in their teens, $35.5 \%$ for patients in their 20 's, $24.3 \%$ for pa-

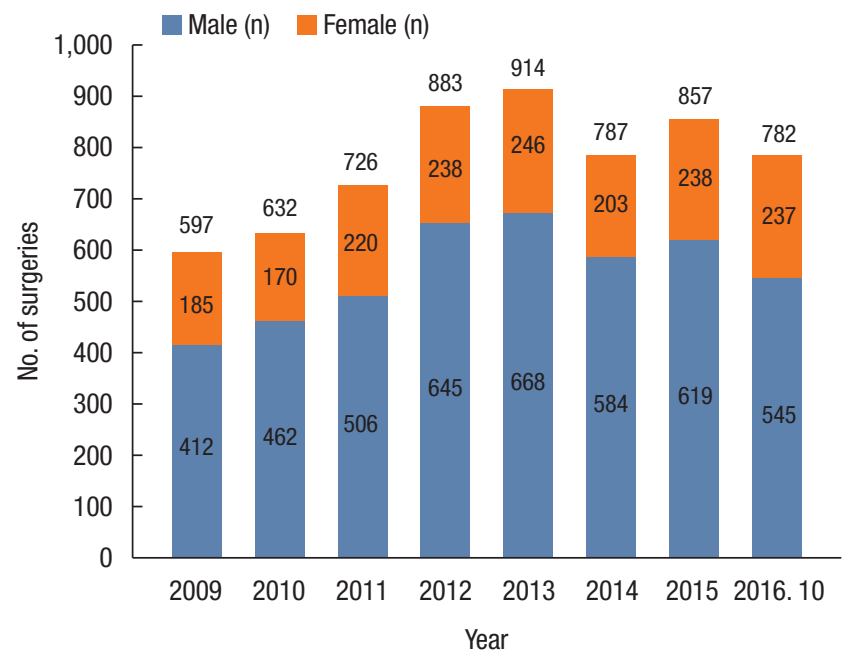

Fig. 1. Annual numbers of surgeries in patients with Crohn disease according to sex.
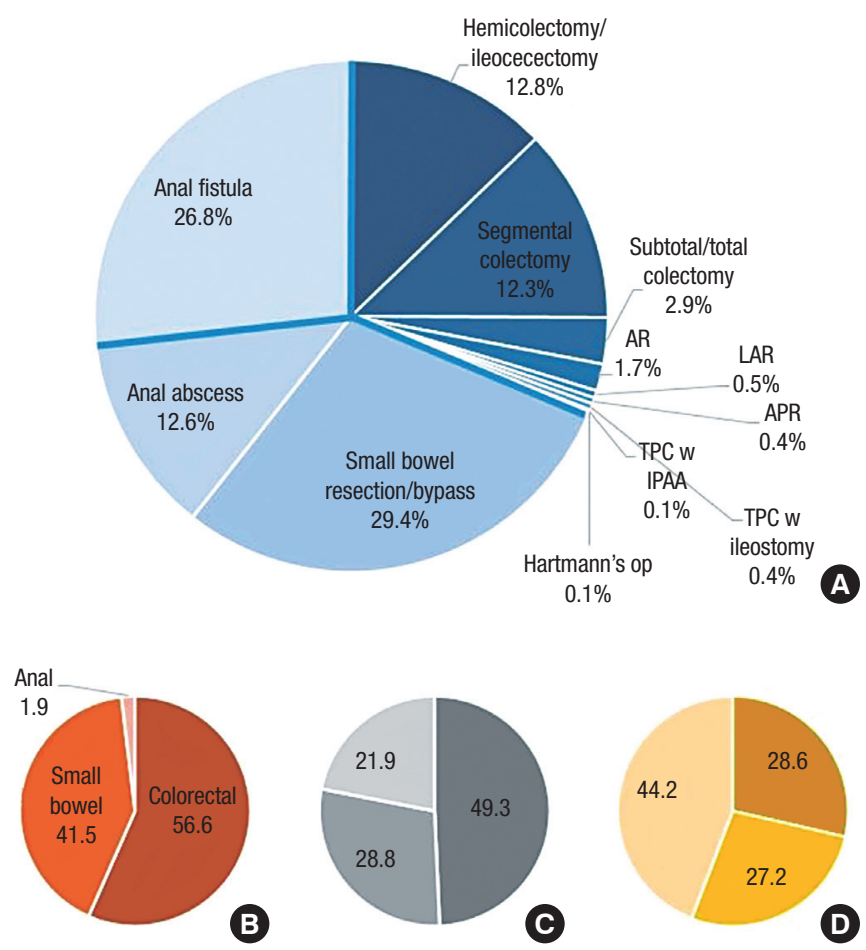

Fig. 2. Types of surgery for Crohn disease (A), and proportions of colorectal surgery, small bowel surgery, and anal surgery (clockwise) performed laparoscopically (B) and in patients with colorectal cancer (C) and in patients who used biologics (D). AR, anterior resection; LAR, low anterior resection; APR, abdominoperineal resection; TPC, total proctocolectomy. tients in their 30 's, and $12.5 \%$ for patients in their 40 's). Because of the nature of the operation, laparoscopic surgery was largely divided between colorectal surgery and small bowel surgery; laparoscopic surgery was particularly prominent in colorectal surgery (Fig. 2B).

About $8 \%$ of all patients receiving operations for CD had colorectal cancer, and that incidence increased slightly by year (Fig. 3B). Among the CD patient with cancer group, $71.0 \%$ were male and $29.0 \%$ were female, which were similar to the values for the group of all patient. In terms of age distribution, the percentage in their 50's or older was higher than that in the group of all patients, and that in their 20's or younger was lower $(7.8 \%$ in teens, $22.7 \%$ in 20 's, $26.2 \%$ in 30 's, $16.4 \%$ in 40 's, $15.3 \%$ in 50 's,
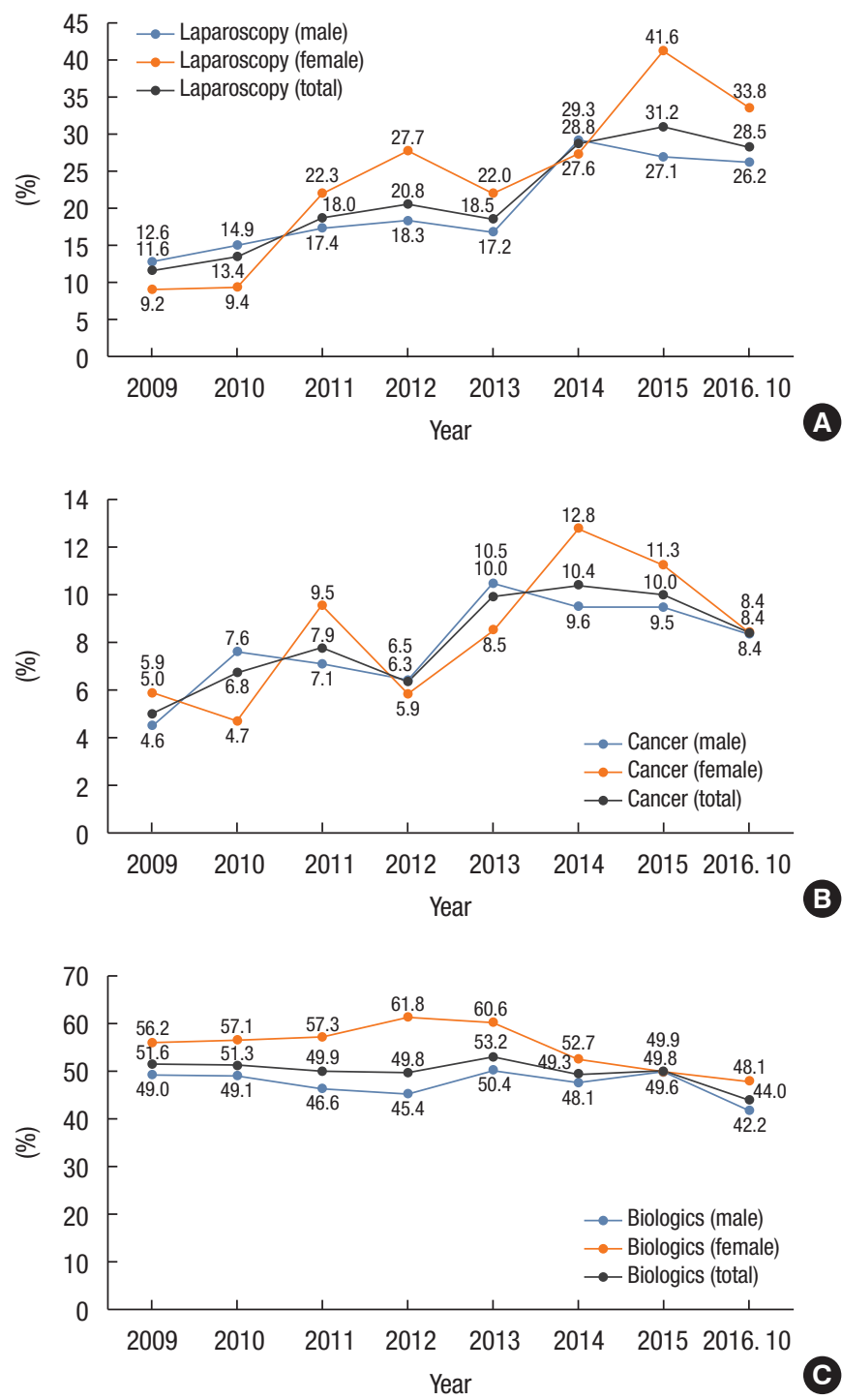

Fig. 3. Changes in the composition of laparoscopic surgery (A), the accompanying rate of colorectal cancer (B), and the use of biologics (C) in patients with Crohn disease. 


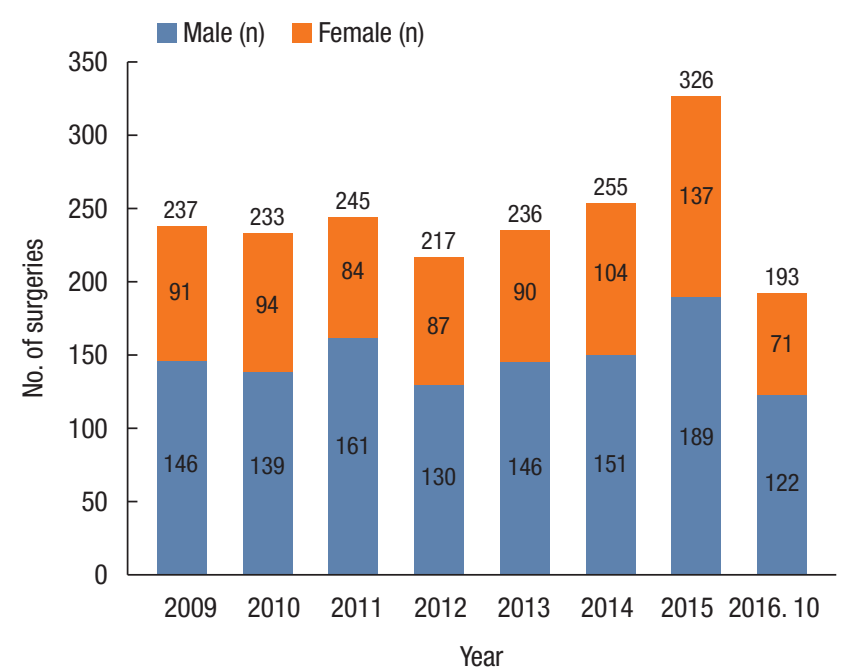

Fig. 4. Annual numbers of surgeries in patients with ulcerative colitis according to sex.

$5.7 \%$ in 60 's, $4.3 \%$ in 70 's, and $1.6 \%$ aged 80 and older). Colon cancer was dominant, accounting for $82.6 \%$ of cancers; $2.2 \%$ were rectosigmoid, and $15.3 \%$ were rectal. Half of the patients with colorectal cancer received colorectal surgery (Fig. 2C).

About half of the patients who underwent surgery for $\mathrm{CD}$ used biologics pre- or postoperatively (Fig. 3C), and that number did not change significantly by year. Of the patients who used biologics, $68.8 \%$ were men and $31.2 \%$ were women. Over the entire period, women were more likely to use biologics (55.4\% for women and $47.7 \%$ for men). The proportion of young patients using biologics was overwhelmingly high (younger than $9,0.6 \%$; teens, $20.0 \%$; 20's, 38.0\%; 30's, 27.3\%; 40's, 10.3\%; 50's, 2.8\%; 60's, 0.8\%; 70 's, $0.4 \%)$. Anal surgery was performed most frequently in patients using biologics, with an average rate of $44.2 \%$ (Fig. 2D).

\section{Ulcerative Colitis}

The average number of operations for UC per year was 247.6, and that number has stayed relatively consistent since 2009 (Fig. 4). On average, $61.0 \%$ of those patients were male, and $39.0 \%$ were female. The sex ratio did not change significantly by year. Of the patients who underwent surgery for UC, $0.5 \%$ were younger than 10 years, $4.3 \%$ were teenagers, $9.6 \%$ were in their 20 's, $13.0 \%$ in their 30 's, $19.1 \%$ in their 40 's, $22.6 \%$ in their 50 's, $15.3 \%$ in their 60 's, $12.2 \%$ in their 70 's, and $3.3 \%$ were 80 or older. Colorectal surgery accounted for more than half of all surgeries performed on UC patients (colorectal surgery, $55.2 \%$; small bowel surgery, 24.6\%; anal surgery, 20.2\%). A total proctocolectomy (TPC) and ileal-pouch anal anastomosis (IPAA) were performed in $13.7 \%$ of these patients (Fig. 5A).

The proportion of laparoscopic surgery increased rapidly from $23.2 \%$ in 2009 to $60 \%$ in 2015 (Fig. 6A). This trend was particularly prominent in women, but the percentage of women who un-
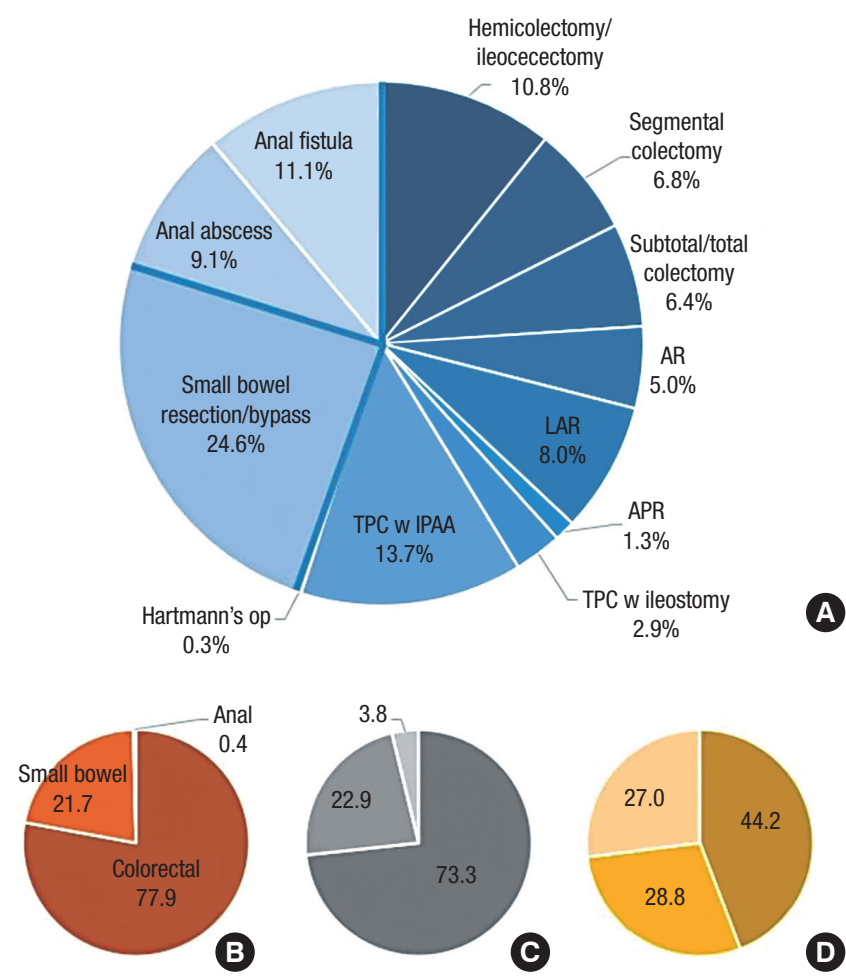

Fig. 5. Types of surgery for ulcerative colitis (A), and proportions of colorectal surgery, small bowel surgery, and anal surgery (clockwise) performed laparoscopically (B) and in patients with colorectal cancer $(C)$ and in patients who used biologics (D). AR, anterior resection; LAR, low anterior resection; APR, abdominoperineal resection; TPC, total proctocolectomy; IPAA, ileal-pouch anal anastomosis.

derwent laparoscopic surgery was not significantly different from that in the total population (male, $60.2 \%$; female, 39.8\%). The age distribution of patients undergoing laparoscopic surgery was similar to that of the total population, but the proportion of patients in their 50's and 60's receiving laparoscopic surgery was slightly higher $(0.3 \%$ under 10 years, $2.4 \%$ in their teens, $6.6 \%$ in their 20 's, $9.4 \%$ in their 30 's, $17.2 \%$ in their 40 's, $26.1 \%$ in their 50 's, $20.0 \%$ in their 60 s, $14.8 \%$ in their 70 's, and $3.1 \%$ older than 80 ). Colorectal surgery accounted for $77.9 \%$ of the laparoscopic surgeries performed for UC (Fig. 5B).

The proportion of patients who underwent surgery for UC and also had colorectal cancer was high and increased rapidly from $27.0 \%$ in 2009 to $79.8 \%$ in 2015 (overall mean 44.7\%) (Fig. 6B). Among the patients with UC who also had colorectal cancer, $60.0 \%$ were male and $40.0 \%$ were female and that did not differ significantly by year. The age distribution of patients with colorectal cancer showed an overall increase in patients in their 50's or older $(0.5 \%$ in their teens, $3.3 \%$ in their 20 's, $7.8 \%$ in their 30 's, $13.6 \%$ in their 40 's, $26.0 \%$ in their 50 's, $21.7 \%$ in their 60 's, $20.6 \%$ in their 70 's, and $6.5 \%$ older than 80 ). Colon cancer occurred in $61.5 \%$ of these patients, rectosigmoid colon cancer in $11.1 \%$, and rectal cancer in $27.4 \%$. The proportion of rectal cancers was 

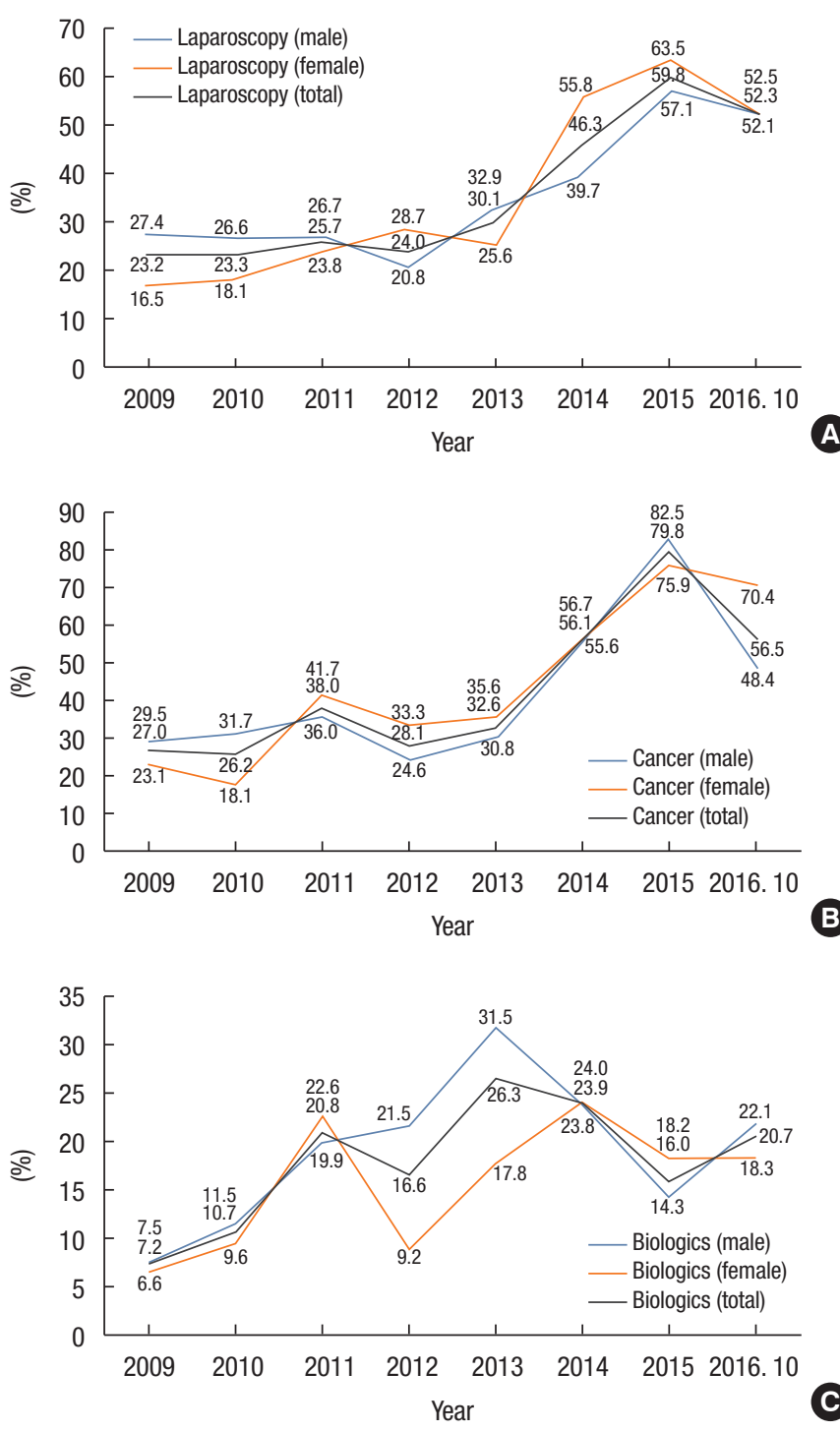

Fig. 6. Changes in the composition of laparoscopic surgery (A), the accompanying rate of colorectal cancer (B), and the use of biologics (C) in patients with ulcerative colitis.

higher than it was in $\mathrm{CD}$ patients. Colorectal surgery was performed in $73.3 \%$ of the patients, and anal surgery was rarely performed in UC patients (Fig. 5C). Among the colorectal surgeries, $12.6 \%$ were anterior resections, $22.5 \%$ low anterior resections, and $3.3 \%$ abdominoperineal resections, which were significantly increased compared to the overall study population.

The proportion of patients who used biologics for UC increased until 2013 and then decreased slightly (Fig. 6C). The average use rate was $17.8 \%$. The proportion of males using biologics was slightly higher than that in the total population (64.8\% for males and $35.2 \%$ for females). In the age distribution of patients using biologics, the proportion of patients under 30 years was higher than it was in the total population, and the rates for patients in their 60's and 70's were significantly lower ( $0.6 \%$ younger than 10 years, $10.5 \%$ in their teens, $14.5 \%$ in their 20 's, $18.6 \%$ in their 30 's, $23.8 \%$ in their 40 's, $21.2 \%$ in their 50 's, $8.1 \%$ in their 60 's, $2.6 \%$ in their 70's). Of the surgical procedures performed in patients using biologics, anal surgery was relatively common at $27.0 \%$ (Fig. 5D).

\section{DISCUSSION}

In our study, we confirmed the demographics and the surgical characteristics of patients undergoing IBD surgery in Korea and how those have changed over time. The incidence of laparoscopic surgery increased significantly in patients with both CD and UC, and the rate of operations for cancer increased rapidly in patients with UC. Patients with CD actively used biologics both before and after surgery. These characteristics are all comparable with the trends in other countries.

In patients with $\mathrm{CD}$, the number of operations increased from 2009 to 2013 and then remained steady. On the other hand, the number of operations for UC remained fairly steady throughout our study period. According to previous reports, the incidence and the prevalence of IBD in Korea have increased steadily [1-3]. However, the rate of bowel resections seems to be rather reduced because the number of IBD operations has stagnated as the incidences and the prevalences of UC and CD have continued to increase, although the lack of previous reports renders direct comparison impossible. This trend is also found in other countries. According to Vind et al. [4], the bowel resection rate in Denmark from 2003 to 2005 was $12 \%$ in CD patients and 6\% in UC patients, which were lower than the rates reported in the 1990's $[5,6]$. Ma et al. [7] reported that the rate of surgical operations in $\mathrm{CD}$ patients decreased by 3.5\% per year between 2002 and 2010; in particular, the rate of emergency surgery decreased by $10.1 \%$ per year.

Previous researchers explained that the decrease in the surgery rate was due to the rapid development of drug therapy $[4,7-9]$. Because biologics, such as infliximab and adalimumab, have been actively used in recent years, in addition to the traditional 5-aminosalicylic acid, steroids, and azathioprine, UC and CD can be well controlled by medical treatment, allowing the rate of surgery to decrease. New drugs, such as golimumab and vedolizumab, continue to be invented and used, so that tendency is likely to continue. We found that about half of $\mathrm{CD}$ patients used biologics and that the number of such patients who underwent anal surgery was relatively high. The use of biologics in patients with UC seems to be lower than it is in patients with CD because UC responds relatively well to traditional medication and does not usually require additional medication after a radical resection. The reader should note that surgery is necessary in certain patients even when they are using biologics, especially in patients with anal lesions. However, because our patients were using biologics both pre- and postoperatively, careful attention should be paid when interpreting our results.

The sex ratio, age distribution, and type of operation in patients 
with CD and UC in Korea are relatively consistent with general knowledge $[3,10]$. In particular, we confirmed that the rate of anal CD in Korea is high; about $40 \%$ of CD patients in this study received anal surgery. We found that the rate of laparoscopic surgery increased significantly in patients with both CD and UC. In recent years, laparoscopic surgery has been performed in about $30 \%$ of CD patients and $60 \%$ of UC patients. Minimally invasive surgery is popular, especially for colorectal surgery. Laparoscopic TPC with IPAA for UC has become common, and similar or better results than open surgery in terms of both short-term and long-term surgical outcomes have been reported [11-15]. Laparoscopy is also used in CD patients, especially for ileocolonic resections, and the Cochrane review has reported no differences in surgical results between laparoscopic and open surgery [16-18]. Laparoscopic surgery is preferred because CD patients might require several operations during their lifetime, and laparoscopy can reduce postoperative adhesions. This tendency is particularly apparent in women because of laparoscopy's cosmetic advantages.

When we analyzed patients with colorectal cancer, we confirmed many changes in the surgical indications for UC during the study period. The proportion of UC patients with colorectal cancer was only $27.0 \%$ in 2009 , but it reached $80 \%$ in 2015 . Because we included patients with a colorectal cancer code that occurred in the year of their operation or earlier, some patients might have been previously diagnosed with colorectal cancer irrespective of their UC status, and others might have been diagnosed with colorectal cancer postoperatively in the year of their operation. However, those cases should present no major problem in confirming the overall tendency. The rate of surgery for colorectal cancer in UC patients was higher than that in CD patients, and recently, most of the patients with UC that underwent surgery had accompanying colorectal cancer recently. The indication for surgery in UC patients has gradually changed from a disease complication, such as medical intractability or toxic megacolon, to malignancy due to the development of medical therapies and the increasing duration of the disease [7, 19-24]. Given present trends, particular attention should be paid to colitis-associated colorectal cancer screening of patients with UC [25-27].

Our study has some limitations. First, the incidence and the prevalence of IBD patients are not known, and information about cumulative surgeries per patient could not be confirmed because our data did not allow us to distinguish individual patients. In addition, short-term and long-term surgical outcomes are not known. Finally, a causal relationship for IBD surgery could not be accurately defined because the biologics and colorectal cancer cohort analyses extracted data as codes in each period. Additional analyses should be performed with raw data, including patient identification information, to produce results that are more accurate. However, our study has important significance in that we used large-scale, nationwide data to analyze about 6,000 cases of $\mathrm{CD}$ and 2,000 cases of UC in Korea, where the incidence of IBD is low, and surgery has been performed sporadically until now.
In conclusion, the numbers of patients who underwent surgery for CD and UC in Korea have increased slightly or stayed the same, and the number of laparoscopic operations has increased rapidly. The use of biologics in $\mathrm{CD}$ has been active, and anal surgery has been performed in many cases. In UC, the use of colorectal cancer as an indication for surgery has increased markedly.

\section{CONFLICT OF INTEREST}

No potential conflict of interest relevant to this article was reported.

\section{ACKNOWLEDGMENTS}

This research was financially supported by The Korean Society of Coloproctology.

The members of the Inflammatory Bowel Disease (IBD) Study Group of the Korean Society of Coloproctology as follows:

Chang-Nam Kim, Eulji University Hospital, Eulji University School of Medicine, Daejeon, Korea; In Kyu Lee, Seoul St. Mary's Hospital, College of Medicine, The Catholic University of Korea, Seoul, Korea; Jae Kyun Ju, Chonnam National University Medical School, Gwangju, Korea; Jong Lyul Lee, Asan Medical Center, University of Ulsan College of Medicine, Seoul, Korea; Ki Yun Lim, Songdo Colorectal Hospital, Seoul, Korea; Kyu Joo Park, Seoul National University College of Medicine, Seoul, Korea; Rumi Shin, Seoul Metropolitan Government-Seoul National University Boramae Medical Center, Seoul, Korea; Seung-Bum Ryoo, Seoul National University College of Medicine, Seoul, Korea; Seung Hyuk Baik, Gangnam Severance Hospital, Yonsei University College of Medicine, Seoul, Korea; Sohyun Kim, College of Medicine, Yeungnam University, Daegu, Korea; Yong Beom Cho, Samsung Medical Center, Sungkyunkwan University School of Medicine, Seoul, Korea; Yong-Geul Joh, Hansol Hospital, Seoul, Korea; Yong Sik Yoon, University of Ulsan College of Medicine, and Asan Medical Center, Seoul, Korea.

\section{REFERENCES}

1. Yang SK, Hong WS, Min YI, Kim HY, Yoo JY, Rhee PL, et al. Incidence and prevalence of ulcerative colitis in the Songpa-Kangdong District, Seoul, Korea, 1986-1997. J Gastroenterol Hepatol 2000;15:1037-42.

2. Yang SK, Yun S, Kim JH, Park JY, Kim HY, Kim YH, et al. Epidemiology of inflammatory bowel disease in the Songpa-Kangdong district, Seoul, Korea, 1986-2005: a KASID study. Inflamm Bowel Dis 2008;14:542-9.

3. Kim HJ, Hann HJ, Hong SN, Kim KH, Ahn IM, Song JY, et al. Incidence and natural course of inflammatory bowel disease in Korea, 2006-2012: a nationwide population-based study. Inflamm Bowel Dis 2015;21:623-30.

4. Vind I, Riis L, Jess T, Knudsen E, Pedersen N, Elkjaer M, et al. In- 
creasing incidences of inflammatory bowel disease and decreasing surgery rates in Copenhagen City and County, 2003-2005: a population-based study from the Danish Crohn colitis database. Am J Gastroenterol 2006;101:1274-82.

5. Langholz E. Ulcerative colitis. An epidemiological study based on a regional inception cohort, with special reference to disease course and prognosis. Dan Med Bull 1999;46:400-15.

6. Munkholm P. Crohn's disease--occurrence, course and prognosis. An epidemiologic cohort-study. Dan Med Bull 1997;44:287-302.

7. Ma C, Moran GW, Benchimol EI, Targownik LE, Heitman SJ, Hubbard JN, et al. Surgical rates for crohn's disease are decreasing: a population-based time trend analysis and validation study. Am J Gastroenterol 2017;112:1840-8.

8. Ramadas AV, Gunesh S, Thomas GA, Williams GT, Hawthorne AB. Natural history of Crohn's disease in a population-based cohort from Cardiff (1986-2003): a study of changes in medical treatment and surgical resection rates. Gut 2010;59:1200-6.

9. Targownik LE, Singh H, Nugent Z, Bernstein CN. The epidemiology of colectomy in ulcerative colitis: results from a populationbased cohort. Am J Gastroenterol 2012;107:1228-35.

10. Jung YS, Han M, Kim WH, Park S, Cheon JH. Incidence and clinical outcomes of inflammatory bowel disease in South Korea, 2011-2014: a nationwide population-based study. Dig Dis Sci 2017; 62:2102-12.

11. Kessler H, Mudter J, Hohenberger W. Recent results of laparoscopic surgery in inflammatory bowel disease. World J Gastroenterol 2011;17:1116-25.

12. Larson DW, Davies MM, Dozois EJ, Cima RR, Piotrowicz K, Anderson K, et al. Sexual function, body image, and quality of life after laparoscopic and open ileal pouch-anal anastomosis. Dis Colon Rectum 2008;51:392-6.

13. Wu XJ, He XS, Zhou XY, Zou YF, Lan P. Safety and feasibility of laparoscopic surgery and open surgery in ulcerative colitis: a meta-analysis. Zhonghua Wei Chang Wai Ke Za Zhi 2008;11:408-13.

14. Wu XJ, He XS, Zhou XY, Ke J, Lan P. The role of laparoscopic surgery for ulcerative colitis: systematic review with meta-analysis. Int J Colorectal Dis 2010;25:949-57.

15. Ahmed Ali U, Keus F, Heikens JT, Bemelman WA, Berdah SV, Gooszen HG, et al. Open versus laparoscopic (assisted) ileo pouch anal anastomosis for ulcerative colitis and familial adenomatous polyposis. Cochrane Database Syst Rev 2009;(1):CD006267.

16. Dasari BV, McKay D, Gardiner K. Laparoscopic versus open surgery for small bowel Crohn's disease. Cochrane Database Syst Rev 2011;(1):CD006956.

17. Maartense S, Dunker MS, Slors JF, Cuesta MA, Pierik EG, Gouma DJ, et al. Laparoscopic-assisted versus open ileocolic resection for Crohn's disease: a randomized trial. Ann Surg 2006;243:143-9.

18. Eshuis EJ, Slors JF, Stokkers PC, Sprangers MA, Ubbink DT, Cuesta MA, et al. Long-term outcomes following laparoscopically assisted versus open ileocolic resection for Crohn's disease. Br J Surg 2010;97:563-8.

19. Itzkowitz SH, Harpaz N. Diagnosis and management of dysplasia in patients with inflammatory bowel diseases. Gastroenterology 2004;126:1634-48.

20. Vagefi PA, Longo WE. Colorectal cancer in patients with inflammatory bowel disease. Clin Colorectal Cancer 2005;4:313-9.

21. Carter MJ, Lobo AJ, Travis SP; IBD Section, British Society of Gastroenterology. Guidelines for the management of inflammatory bowel disease in adults. Gut 2004;53 Suppl 5:V1-16.

22. Herszenyi L, Miheller P, Tulassay Z. Carcinogenesis in inflammatory bowel disease. Dig Dis 2007;25:267-9.

23. Canavan C, Abrams KR, Mayberry J. Meta-analysis: colorectal and small bowel cancer risk in patients with Crohn's disease. Aliment Pharmacol Ther 2006;23:1097-104.

24. Shaukat A, Virnig DJ, Salfiti NI, Howard DH, Sitaraman SV, Liff JM. Is inflammatory bowel disease an important risk factor among older persons with colorectal cancer in the United States? A population-based case-control study. Dig Dis Sci 2011;56:237883.

25. Van Assche G, Dignass A, Bokemeyer B, Danese S, Gionchetti P, Moser G, et al. Second European evidence-based consensus on the diagnosis and management of ulcerative colitis part 3: special situations. J Crohns Colitis 2013;7:1-33.

26. Kornbluth A, Sachar DB; Practice Parameters Committee of the American College of Gastroenterology. Ulcerative colitis practice guidelines in adults: American College Of Gastroenterology, Practice Parameters Committee. Am J Gastroenterol 2010;105:501-23.

27. Mowat C, Cole A, Windsor A, Ahmad T, Arnott I, Driscoll R, et al. Guidelines for the management of inflammatory bowel disease in adults. Gut 2011;60:571-607. 